\title{
REALIDADE VIRTUAL: MENOS BARREIRAS MAIS IMAGINAÇÃO NO PROCESSO DE ENSINO-APRENDIZAGEM NA MODALIDADE EAD
}

\author{
SÃO PAULO/SP JULHO/2018
}

\author{
Giovani Pereira dos Santos - Laureate - gpsantos@eadlaureate.com.br \\ Cláudia Leite Machado - Laureate - claudia.machado@eadlaureate.com.br \\ Alexsandra dos Santos Rodrigues - Laureate - alexsandra.rodrigues@eadlaureate.com.br \\ Ângelo Gomes da Silva - Laureate - agsilva@eadlaureate.com.br \\ Magnus Henry da Silva Marques - Laureate - magnus.marques@eadlaureate.com.br \\ Osório Moreira Couto Júnior - Laureate - osorio.junior@eadlaureate.com.br \\ Danilo Santiago Gomes Valentim - Laureate - dsvalentim@eadlaureate.com.br
}

Tipo: Relato de Experiência Inovadora (EI)

Categoria: Métodos e Tecnologias

Setor Educacional: EDUCAÇÃO SUPERIOR

\section{RESUMO}

Considerando a possibilidade e oportunidade da experimentação dos conteúdos acadêmicos pelo estudante por meio da Realidade Virtual, este artigo, a título de relato de experiência inovadora, tem como objetivo apontar as contribuições deste recurso tecnológico aplicado no processo de ensinoaprendizagem na modalidade EaD. Para tanto, procede-se os apontamentos referenciais juntamente com a pesquisa aos usuários - professores e estudantes -. Desse modo, observa-se uma percepção positiva em relação ao uso dos recursos da tecnologia Realidade Virtual, o que permite concluir que conteúdos que geram imersão e experiências aos estudantes colaboram com o processo de ensinoaprendizagem.

Palavras-chave: Educação a Distância, Tecnologia da Informação, Realidade Virtual 


\section{INTRODUÇÃO}

Em um mundo que se apresenta em constante evolução e mudanças de paradigmas, a urgência de transformação nunca foi tão necessária, principalmente na área da educação. Com alto fluxo de informações e necessidade de formação continuada, o estudante traz consigo novas ânsias uma vez que as influências do cinema, da economia, das redes sociais, do esporte, da mídia, etc., juntamente com os avanços dos recursos tecnológicos, conceberam uma nova consciência cada vez mais "conectada" com o mundo ao seu redor.

A modalidade de ensino a distância se apresenta como uma alternativa para esta nova realidade em que espaço e tempo foram reconfigurados. No entanto, apesar das altas taxas de crescimento e avanços percebidos pelo uso de diversos recursos tecnológicos, a educação a distância ainda se depara com diversos desafios, entre eles, se desvencilhar do modelo de transmissão de informação.

Com o dinamismo do mundo contemporâneo, não é suficiente ter a informação, é preciso saber buscá-la, renová-la, transformá-la em funções psicológicas superiores, ou seja, em habilidades de lidar com o inédito. A partir da utilização dos ambientes didáticos virtuais e as suas diversas possibilidades de comunicação, a Realidade Virtual se apresenta como uma alternativa na perspectiva de proporcionar novas experiências. De acordo com Christopher D. Wickens e Polly Baker (1995):

Realidade Virtual envolve a criação de experiência multissensorial de um ambiente (seu espaço e eventos) através de meios artificiais e eletrônicos; mas esse ambiente incorpora um número suficiente de características do mundo não artificial que é experimentado como "realidade". (WICKENS \& BAKER, 1995, p. 514, tradução dos autores)[1]

A ilusão de estar em outra realidade, de poder observar outros espaços com a possibilidade de acompanhar eventos históricos, permite pensar o processo de ensinoaprendizagem baseado na experiência vivida, que não é aquilo que acontece, e sim aquilo que acontece no indivíduo, que o transforma e que o toca. $O$ artigo que aqui se propõe, tem como objetivo demonstrar a viabilidade e contribuição da utilização deste instrumento, a Realidade Virtual na educação - em especial para a modalidade a distância - pois permite a imersão e experimentação do estudante em relação ao conteúdo exposto.

Antes de dissertar sobre o assunto tema central deste artigo, faz-se necessário evidenciar alguns aspectos relacionados ao ensino a distância: o desenvolvimento das tecnologias; algumas informações sobre o perfil do estudante a distância e alguns desafios da educação a distância. Após a exposição destes pontos, discutir-se-á sobre a aplicabilidade da Realidade Virtual.

\section{Possibilidades Tecnológicas}


Com o advento da internet e com o desenvolvimento de conexões de alta velocidade que se sobrepõe as barreiras físicas e geográficas, pode-se pensar no que Marshall McLuhan nomeou de "aldeia global" (MCLUHAN, 2002, p. 111) onde “(...) o meio é a mensagem" (ibdem, p. 22) surgindo assim uma nova maneira de viver, onde "o mundo visível já não é mais uma realidade e o mundo invisível já não é mais um sonho." (ibdem, p. 52).

Associado a esta transformação o uso da tecnologia em todos os setores, inclusive em ambientes educacionais, trouxeram novas perspectivas em relação ao ensino: uma necessidade de inovação constante; um repensar de processos e o desenvolvimento de habilidades de pensamento.

Linard (1996, p. 16) propõe:

[...] pensar as TICs[2] desde uma perspectiva ética (das finalidades sociais da educação) e estética (das formas e linguagens de que se constituem tais técnicas) e afirma que seu objetivo não é recusar a razão ou as ciências exatas, nem as novas tecnologias, mas compreendê-las melhor para integrá-las à educação, de modo que permita que o aprendente se aproprie delas e não seja dominado por sua lógica.

Usar a tecnologia de última geração em si, não resolve e não garante o aprendizado se as pessoas não souberem utilizá-la da forma efetiva. Oportuno sinalizar que uma das mudanças fundamentais na educação superior é uma maior diversidade de perfis dos estudantes[3]. Essa diversidade apresenta desafios para os docentes, bem como para a equipe institucional envolvida. Se não era comum que os docentes do ensino superior diversificassem suas abordagens, agora, neste novo contexto, torna-se necessário que todos os cursos desenvolvam uma grande variedade de abordagens e formas de aprender. O uso inteligente das mídias e tecnologias que considera as diferenças permite comunicação, ampliação de conhecimento, interação e experimentação.

\section{O processo de ensino-aprendizagem}

O ensino-aprendizagem na modalidade $\mathrm{EaD}$ tem como característica o seu processo constante de evolução. Esta é impulsionada, entre outros, pelos avanços tecnológicos com a possibilidade da utilização de diversas mídias e também pelos estudantes que cada vez mais percebem a potencialidade da modalidade.

Antes de falar sobre a aplicabilidade da Realidade Virtual no ensino a distância, vale resgatar alguns pontos relacionados ao processo de ensino-aprendizagem. $O$ resgate deste processo permitirá maior clareza e objetividade no entendimento da aplicabilidade da realidade virtual no ensino-aprendizagem na modalidade EaD proposta neste artigo. Com intuito de entender a significância da qualidade do estímulo no processo de ensinoaprendizagem, para efeito de ilustração, será utilizado o modelo proposto por (MAYER, 
1981 apud BORUCHOVITCH, 1999, p. 6). O modelo ilustra passo a passo o fluxo da informação ao longo do processo de transformação da informação em conhecimento.

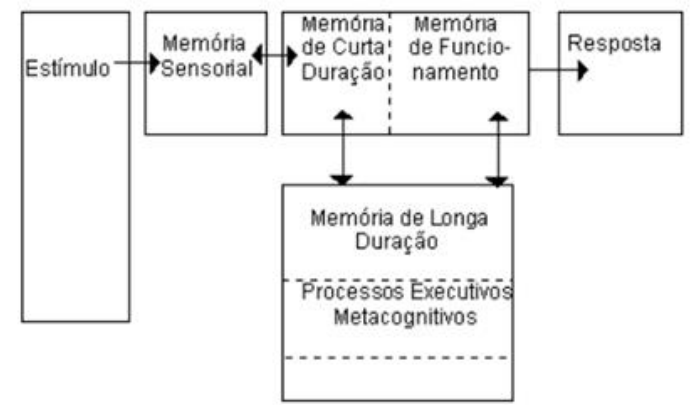

Figura 1: Modelo de Processamento da Informação Humana (Traduzido e adaptado por Mayer, 1981, citado por Boruchovitch, 1999)

No processamento da informação, o primeiro ponto refere-se ao estimulo que vem do meio que pode ser diverso: visual, sonoro, etc.; a partir deste estímulo, a informação migra para a memória sensorial iniciando-se assim a possibilidade de armazenamento da informação. A partir do estágio seguinte, ou seja, a memória de curta duração ou também chamada de memória de funcionamento, se dá a possibilidade da informação ser registrada e armazenada para ser utilizada em futuras ocasiões, já as que não entram na memória de curta duração são completamente perdidas.

O processo de transformação da informação inicia-se no momento em que entra no registro sensorial e é codificada. De acordo com (DEMBO,1988 apud BORUCHOVITCH, 1999 , p. 6), "a maneira pela qual a informação é codificada e integrada na memória, bem como a extensão e profundidade da integração, afeta a facilidade com que a informação pode ser recuperada, posteriormente".

E complementa, "enquanto a informação precisa ser ensaiada para se manter na memória de curta duração, ela precisa ser elaborada para ir para a memória de longa duração, isto é, precisa ser classificada, organizada, conectada e armazenada com a informação que já existe na memória de longa duração". (BORUCHOVITCH, 1999, p. 7).

$\mathrm{Na}$ contemporaneidade, a quantidade de informações que circulam é imensa, exigindo capacidade de atualização e desenvolvimento de novas habilidades. No processo de ensino-aprendizagem, o cuidado para promover um estimulo de qualidade pode representar o start necessário para que o estudante se interesse pelo conteúdo apresentado e compreenda o seu valor e aplicabilidade.

As instituições que oferecem cursos na modalidade EaD buscam a utilização dos diversos recursos tecnológicos e disponibilizam os conteúdos acadêmicos por meio de diversas mídias, como por exemplo: livro-texto, vídeo-aulas, webconferências, podcast, 
etc. Este esforço tem como objetivo atender as particularidades de cada estudante, uma vez que eles podem escolher de que forma querem abordar o conteúdo e também proporcionar um ensino de qualidade, permitindo assim a ampliação do conhecimento. Pensando neste dinamismo necessário, a utilização do recurso realidade virtual apresenta-se como possibilidade para permitir maior interatividade entre os conteúdos acadêmicos e os estudantes. Antes de abordar estas possibilidades, cabe aqui uma breve explicação acerca deste recurso tecnológico.

\section{Realidade virtual}

Segundo Lemos (2002, p. 155):

A RV é um ambiente simulado que permite interações, onde os usuários recebem estímulos corporais. O corpo real migra para um mundo de pura informação. Assim, as tecnologias da RV nos permitem não só olhar uma paisagem, por exemplo, mas experimentar uma interação tátil, como se estivéssemos dentro de um novo mundo.

$\mathrm{Na}$ educação, a realidade virtual é algo relativamente novo e por se tratar de uma tecnologia que carece de altos investimentos sejam financeiros, sejam de tempo, além da composição de uma equipe especializada na produção dos conteúdos, poucas as instituições exploram este recurso tecnológico aplicado à educação.

Essa tecnologia, não raro, é confundida com game, no entanto, embora utilize diversos princípios dos games na construção dos cenários, na movimentação dos personagens, entre outros, volta-se mais no sentido de permitir experimentação, com a possibilidade de explorar e aprender, excursionando pelo ambiente virtual, por cenários reais, que podem ajudar na compreensão da proposta porque aproxima o estudante do objeto de estudo, levando-o a lugares e eventos que o ambiente escolar encontraria dificuldade para permitir esta vivência.

Na realidade virtual aplicada à educação, o estudante tem a sensação de interação com o mundo real, por meio da imersão no ambiente virtual. É uma forma de encantar o estudante, chamando sua atenção para o conteúdo e motivando-o a aprender de uma forma mais interessante e interativa. Assim, o resultado do seu aprendizado poderá ser melhor, uma vez que fica mais fácil reter a informação.

Percebe-se a pluralidade que o tema pode atingir em sintonia com a fundamentação teórica das disciplinas. Pensando em uma melhor maneira de demonstrar as potencialidades da tecnologia de uma forma mensurável, direciona-se neste momento a medição de percepções de envolvidos em relação a tecnologia realidade virtual.

$\mathrm{Na}$ IES (Instituição de Ensino Superior), o trabalho desenvolvido concentra-se na elaboração de conteúdos compostos por temas transversais, que podem ser utilizados por vários cursos, em várias disciplinas. O primeiro vídeo desenvolvido em 2016 foi o Descobrimento do Brasil, que contempla um cenário de sete quilômetros do início ao 
fim. Em seguida, a equipe iniciou a elaboração do segundo, um vídeo do Coliseu, uma das maiores obras de engenharia, triunfo da excepcional capacidade inventiva e arquitetônica dos romanos.

A realidade virtual refere-se à utilização de tecnologia de games, onde observa-se um jogo em que ao invés do estudante controlar o desenrolar das atividades, o desenvolvedor condiciona a progressão das atividades, visualização e resultados inerentes. Os vídeos são elaborados com tecnologia 3D, 360 graus e hospedados no Youtube, desta forma, não demandam uma habilidade especifica para interação, basicamente conexão com a internet, micro com mouse, tablet ou celular.

Atualmente, a IES conta com vídeos de realidade virtual que são utilizados em diversas disciplinas e cursos, apresentando-se assim como mais um recurso tecnológico que a instituição e o corpo docente podem utilizar para ampliar as potencialidades do processo de ensino-aprendizagem.

$\mathrm{Na}$ busca de mesurar os diversos resultados da utilização desta tecnologia, entre os dias 30/04/2018 e 18/05/2018 foram aplicados dois testes: um destinado ao corpo docente no sentido de identificar qual a percepção dos professores em relação a tecnologia; e outro, aos estudantes, buscando saber se a utilização da tecnologia colabora para melhor compreensão dos conteúdos.

A pesquisa direcionada os professores mostrou os seguintes resultados:

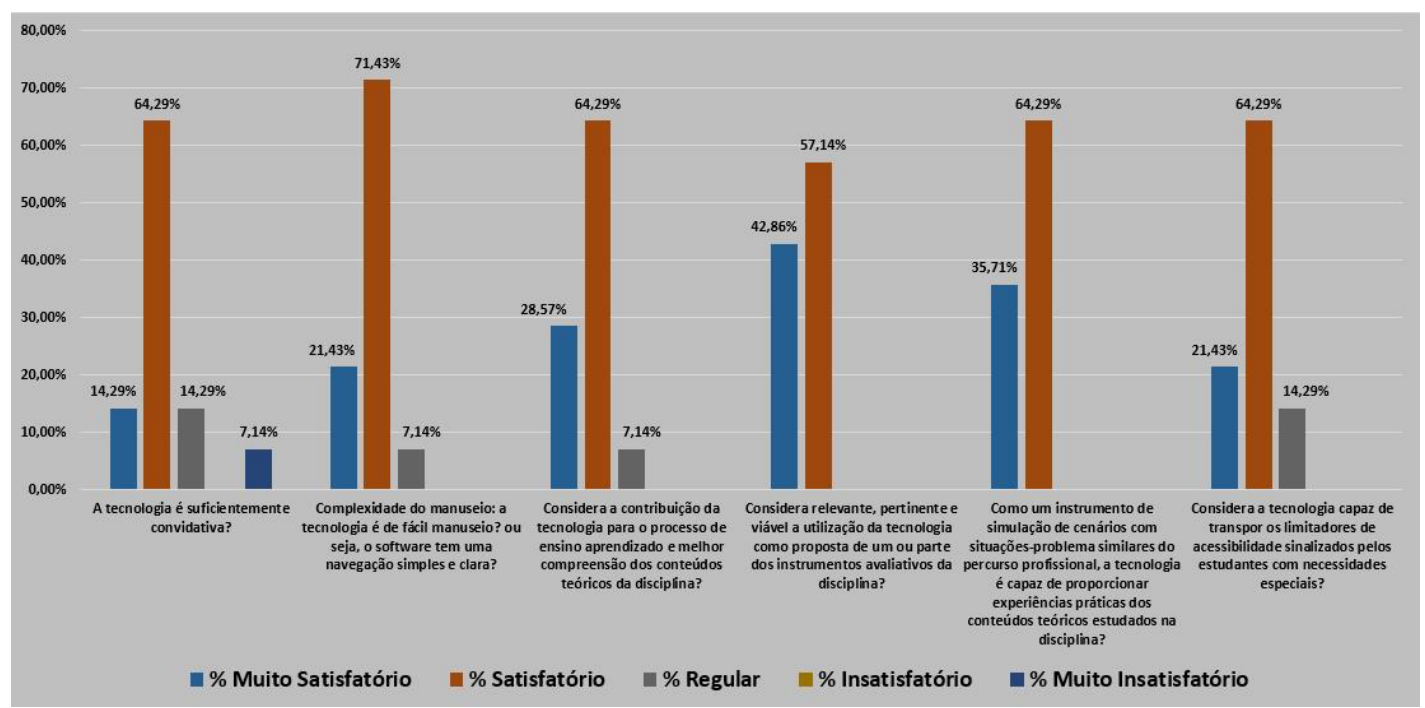

Figura 2: Questionário de investigação: Tecnologia Realidade Virtual (Professores) 


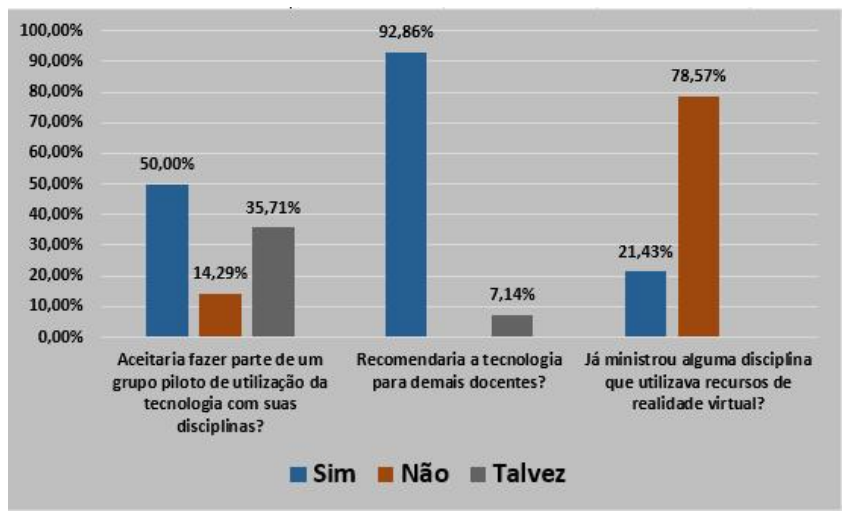

Figura 3: Questionário de investigação: Tecnologia Realidade Virtual (Professores)

Com os índices $64,29 \%$ satisfatório no que tange aos critérios "A tecnologia é suficientemente convidativa" e "Considera a contribuição da tecnologia para o processo de ensino aprendizagem e melhor compreensão dos conteúdos teóricos da disciplina", os professores percebem a realidade virtual como uma alternativa capaz de provocar um estímulo para a proposta pedagógica por ele estabelecida. Devido ao seu critério de navegação simples e clara reconhecido pela pesquisa com satisfação em 71,43\%, tal aspecto possibilita uma maior aplicabilidade desta tecnologia, haja vista os perfis diferenciados dos estudantes na modalidade EaD. Com 64,29\% de satisfação no item acessibilidade, os professores sinalizam que a realidade virtual, ainda que embrionária na educação contribui com o processo de inclusão social. Como instrumento de simulação de cenários $64,29 \%$ dos professores consideram satisfatório e 35,71\% muito satisfatório. Isso indica que os professores consideram a tecnologia de realidade virtual como uma ferramenta que permite o contato e vivência na prática pelos estudantes em relação ao conteúdo apresentado. Com o critério "Considera relevante, pertinente e viável a utilização da tecnologia como proposta de um ou parte dos instrumentos avaliativos da disciplina", nota-se o professor considera a possibilidade de avaliar em parte o entendimento dos conteúdos apresentados pela tecnologia que associa prática e vivência de experiências.

Todos os itens pesquisados apresentaram perspectivas positivas em relação à utilização da realidade virtual, com destaque no item "Recomendaria tecnologia para seus colegas" com 92,86\%. Apesar de poucos professores $(21,43 \%)$ já terem utilizado o recurso em suas disciplinas, 50,0\% aceitaria fazer parte de grupo piloto. Isso demonstra que os professores percebem a contribuição que o uso da tecnologia pode trazer para o EaD.

Direcionando as análises dos resultados da pesquisa realizada com os estudantes, conclui-se que: 


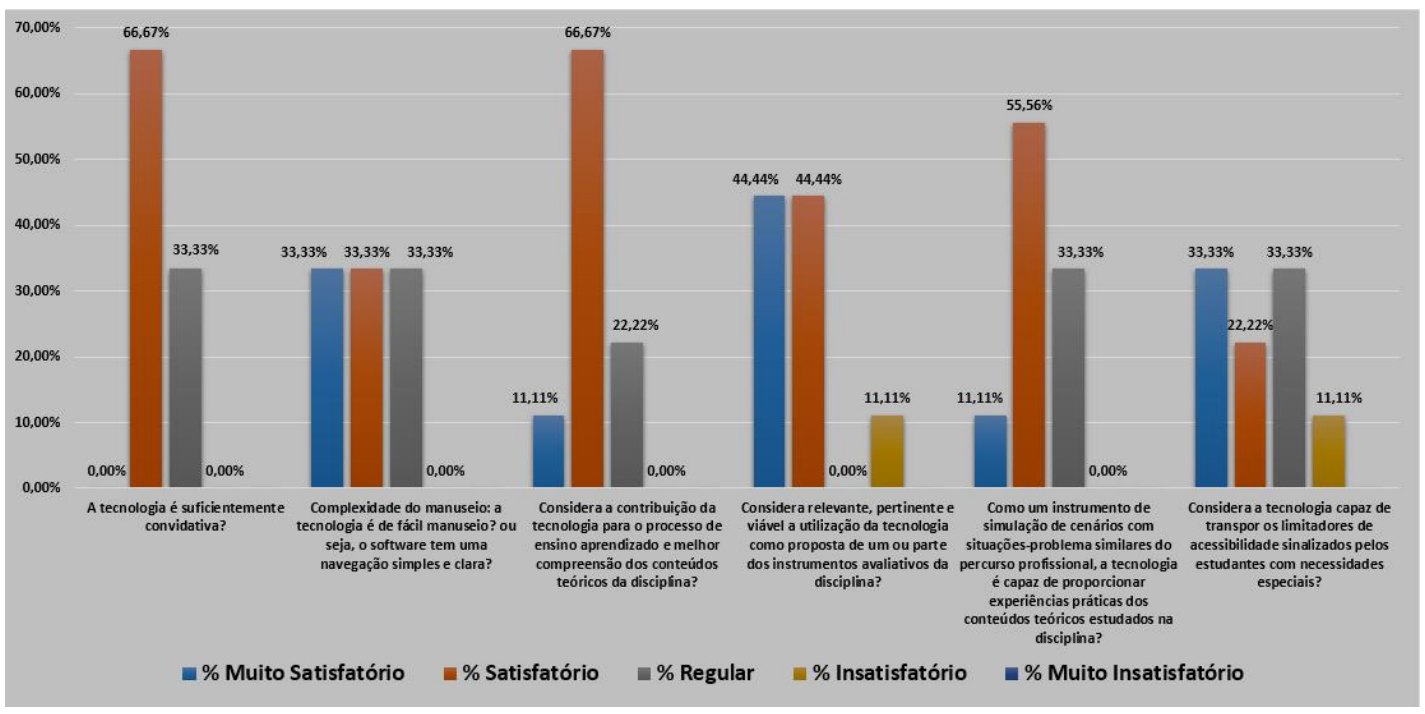

Figura 4: Questionário de investigação: Tecnologia Realidade Virtual (Estudantes)

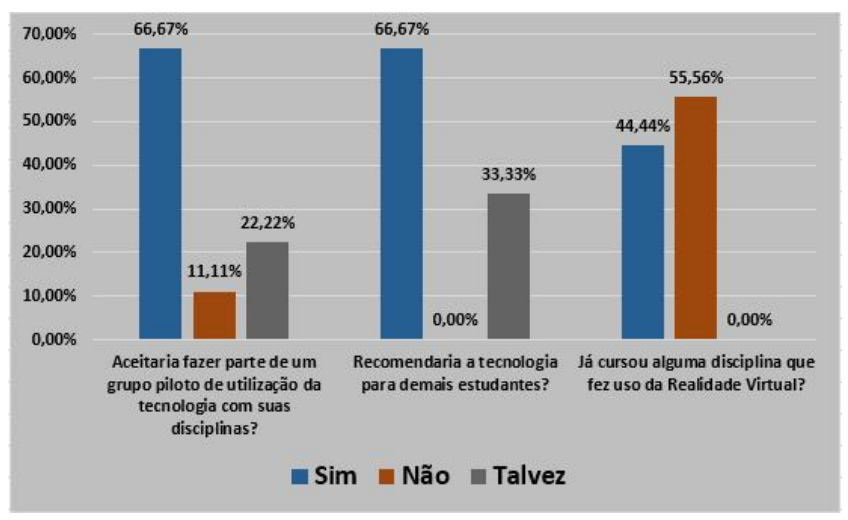

Figura 5: Questionário de investigação: Tecnologia Realidade Virtual (Estudantes)

Analisando a pesquisa aplicada aos estudantes, o resultado mostra que a maioria $66,67 \%$ afirma que é satisfatório, ou seja, a tecnologia é convidativa porém com percentual a ser melhorado, e 33,33\% disseram que este item mantem-se no patamar de regular. Sobre a navegação e o manuseio, as respostas ficaram distribuídas entre muito satisfatório, satisfatório e regular; logo, entende-se que a resposta é positiva, entre outras perguntas, analisadas conforme os gráficos.

O que se percebe a partir da pesquisa é que os estudantes apresentam uma grande disposição para a experimentação de novos recursos no ensino a distância: $66,67 \%$ aceitariam fazer parte de um grupo piloto de utilização da realidade virtual. Isso demonstra um dos grandes diferenciais do ensino na modalidade a distância, a disposição para buscar o progresso e experimentar a transformação e inovação. Destaca-se, também, a percepção por parte dos estudantes da contribuição da tecnologia para o processo de ensino-aprendizagem e a capacidade de simulação oferecida pela tecnologia. Em ambos os itens, todas as respostas ficaram acima do nível 
regular. No quesito "Considera relevante, pertinente e viável a utilização da tecnologia como proposta de um ou parte dos instrumentos avaliativos da disciplina" observa-se que $44,44 \%$ sinalizam como muito satisfatório e $44,44 \%$ satisfatório. Isso possibilita perceber a importância da aplicação prática e vivências de experiências relacionadas ao conteúdo. Em relação ao critério de acessibilidade as respostas ficarão equilibradas entre muito satisfatório, satisfatório e regular, indicando assim, pela visão dos estudantes, espaço para ampliação.

Dos estudantes que participaram da pesquisa e experimentaram a tecnologia para responder à pesquisa ou que cursaram disciplinas que fizeram uso da tecnologia, $66,67 \%$ recomendariam. Isso indica que eles percebem a contribuição da Realidade Virtual em seu processo de ensino-aprendizagem.

\section{CONSIDERAÇÕES FINAIS}

Objetivou-se saber com a pesquisa a relação com as potencialidades pedagógicas da realidade virtual. Partiu-se de um cenário contemporâneo que tem como características um fluxo veloz de informações e constantes mudanças de cenários, relacionando estes aspectos com um modelo de educação (baseado na transmissão de informações) que já não dá mais conta de atender aos desejos, anseios e expectativas dos estudantes, uma vez que eles já têm acesso às informações em tempo real.

Direcionou-se então o estudo para uma educação que possibilita a experiência e é neste ponto que entra a realidade virtual e sua capacidade de proporcionar a imersão aos conteúdos apresentados.

Não se imagina que o simples uso da tecnologia realidade virtual seja a solução, mas acredita-se que atualmente não é a distância que separa professor-estudante e estudantes-estudantes, que impede o processo de ensino-aprendizagem, e sim a qualidade do estímulo e possibilidade que este provoca ou não na vivência de experiência, de acordo com os estudos de Boruchovitch (1999). Neste sentido, defendese que o uso efetivo da realidade virtual pode proporcionar este estímulo de qualidade comprovados pelas referências teóricas e pesquisa, bem como os resultados.

A realidade virtual permite imersão por meio de um vídeo $360^{\circ}$ graus para que todos os detalhes sejam absorvidos, vividos na íntegra, dando a sensação de "realidade". Funciona porque estimula os sentidos, tanto visuais, quanto auditivos. Para o estudante é enriquecedor, uma vez que propicia uma experiência de contato com o conteúdo de modo diferente do habitual. É a oportunidade de compreender o que acontece, na prática, mas sem sair do seu espaço, seja sua casa ou a própria universidade. A metodologia atrai a atenção porque utiliza uma ferramenta nova, incorpora os conhecimentos teóricos e apresenta estes por meio de um processo criativo que 
estimula a imaginação e a vivência de experiência.

Neste contexto, cabe ponderar acerca do quanto a Educação a Distância absorve a utilização das tecnologias em andamento e desenvolvimento que surgem ao seu favor. A realidade virtual pode ser uma destas tecnologias que contribuirá para o processo de derrubar as paredes e ampliar a sala de aula.

\section{REFERÊNCIAS BIBLIOGRÁFICAS}

ABED. Associação Brasileira de Educação a Distância. Censo EaD.br: relatório analítico da aprendizagem a distância no Brasil. São Paulo: Pearson Education do Brasil, 2017. BORUCHOVITCH, Evely. Estratégias de aprendizagem e desempenho escolar: Considerações para a prática educacional. Psicología Reflexão e Crítica. Porto Alegre: vol. 12, no 002, 1999, p. 361-376.

LEMOS, André. Cibercultura, tecnologia e vida social na cultura contemporânea. Porto Alegre: Sulina. 2002.

LINARD, Monique. Des machines et des hommes. Paris: L'Harmattan. 1996.

MCLUHAN, Marshall. Os meios de comunicação como extensões do homem. São Paulo: Cultrix, 2002. Disponível em: https://edisciplinas.usp.br/pluginfile.php/352425/mod _resource/content/1/MCLUHAN\%2C\%20Marshall\%20-\%200s\%20Meios\%20de\%20Co municac\%CC\%A7a\%CC\%830\%20como\%20Extenso\%CC\%83es\%20do\%20Homem.pdf . Acesso em: 30 mai 2018.

PLANALTO. Lei no 10.172, de 9 de janeiro de 2001. Disponível em: Acesso em 18 mai 2018.

WICKENS, Christopher D.; BAKER, Polly. Cognitive Issues in Virtual Reality. in: BARFIELD, Woodrow; FURNESS III; Thomas A. . Virtual Environments and Advanced Interface Design. $1^{\mathrm{a}}$ Ed. New York: Oxford University Press, 1995, p. 514- 541.

[1] Texto original: Virtual Reality involves the creation of multisensory experience of an environment (its space and events) through artificial, electronic means; but that environment incorporates a sufficient number of features of the non-artificial world that it is experienced as "reality".

[2] TICs: Tecnologias da Informação e Comunicação.

[3] Censo EaD 2016 (p. 85-88) 